\title{
THE TRANSLATIONAL LATTICE-VIBRATION RAMAN SPECTRUM OF SINGLE-CRYSTAL ICE Ih
}

\author{
By P. FAure and A. Chosson \\ (Laboratoire de Spectrométrie Raman-Laser, Centre Universitaire de Savoie, 7301I \\ Chambéry, France)
}

\begin{abstract}
We present the Raman spectra in natural and polarized light of ice Ih monocrystals in the region of the translational frequencies. These spectra are of better quality and higher resolution than previous spectra from monocrystals, and demonstrate the value of the investigation of single crystals by this technique, in spite of the proton disorder. In order to explain the observations we use the model of simultaneous activity of the modes allowed in $D_{6 h}$ symmetry and the modes allowed by the proton disorder. By analogy with the interpretation of the phenomena observed in ordered piezoelectric crystals, we suggest that the existence of translation frequencies up to $c .320 \mathrm{~cm}^{-1}$ is due to the splitting between transverse and longitudinal optical modes. On this basis, an initial simple dynamical model using only three parameters permits an interpretation of the Raman spectrum. The probable presence of directional effects in ice Ih argues in favour of the proposed explanation.
\end{abstract}

Résumé. Le spectre Raman des vibrations de translation du réseau de la glace Ih monocristalline. Nous présentons des spectres Raman, en lumière naturelle et polarisée, de monocristaux de glace Ih, dans la région des fréquences de translation. Ces spectre; sont de meilleure qualité et mieux résolus que les spectres antérieurs de monocristaux, et prouvent l'intérŝt de l'étude de monocristaux par cette technique, malgré le désordre des protons. Afin de rendre compte de; spectre; observés, nous adoptons le schéma de l'activité simultanée des modes autorisés dans la symétrie $D_{6 h}$ et des modes autorisés par le désordre des protons. Par analogie avec l'interprétation des phénomènes observés dans les cristaux ordonnés piezoélectriques, nous proposons d'expliquer l'existence de fréquence; de translation jusqu'à environ $320 \mathrm{~cm}^{-1}$ par des séparations entre modes optiques transverses et longitudinaux. Sur ce principe, un premier modèle dynamique simple, à trois paramètres seulement, permet d'entreprendre une interprétation du spectre Raman. La présence probable d'effets directionnels dans le glace Ih est un argument en faveur de l'explication proposée.

Zusammenfassung. Das Ramanspektrum der Translationsgitterschwingungen von Eis-Ih-Einkristallen. Wir legen Ramanspektren von Eis-Ih-Einkristallen in natürlichem und polarisiertem Licht im Bereich der Translationsfrequenzen vor. Diese Spektren haben eine bessere Qualität und höhere Auflösung als frühere Spektren von Eiskristallen und zeigen den Wert der Untersuchung von Einkristallen mit Hilfe dieser Technik, ungeachtet der Protonenunordnung. Zur Erklärung der Beobachtungen benützen wir das Modell der gleichzeitigen Anregung derjenigen Moden, die in der $D_{6 h}$-Symmetrie und durch die Protonenunordnung erlaubt sind. Entsprechend der Deutung der Erscheinungen, die an geordneten piezoelektrischen Kristallen beobachtet wurden, schlagen wir vor, dass das Auftreten von Translationsfrequenzen bis zu etwa $320 \mathrm{~cm}^{-1}$ von der Aufspaltung transversaler und longitudinaler optischer Moden herrührt. Auf dieser Grundlage erlaubt ein erstes, einfaches dynamisches Modell, das nur drei Parameter benützt, die Ramanspektren zu deuten. Das mögliche Vorhandensein von Richtungseffekten in Eis Ih spricht für die vorgeschlagene Erklärung.

\section{INTRODUGTION}

Interest in spectroscopic investigations of the different forms of ice mainly lies in the fact that ice is a typical hydrogen-bonded crystal, the simplest one, and some of its crystalline forms are orientationally disordered.

The first spectra of ice Ih single crystals obtained with modern Raman-laser techniques were those of Faure (unpublished) and Faure and Chosson ( $\left[{ }^{c_{1}}{ }_{97} \mathrm{I}\right]$ ) for the translational region, and these spectra already give a good idea of the general shape of the spectrum and of some of its details. More detailed spectra, but with polycrystalline samples, were taken by Wong and others (1973) and Wong and Whalley (1976).

The first aim of this paper will be to obtain a better knowledge of the details of the spectrum of the single crystal using polarized light. We then propose to account for the existence of translational frequencies up to $c .320 \mathrm{~cm}^{-1}$ by TO-LO splittings in connection with which we discuss briefly a dynamical model already presented (Faure and Chosson, $\left[{ }^{c_{1}}{ }_{97} \mathrm{I}\right]$; Faure and Kahane, $\left.\left[{ }^{\mathrm{c}} \mathrm{I} 97 \mathrm{I}\right]\right)$. 


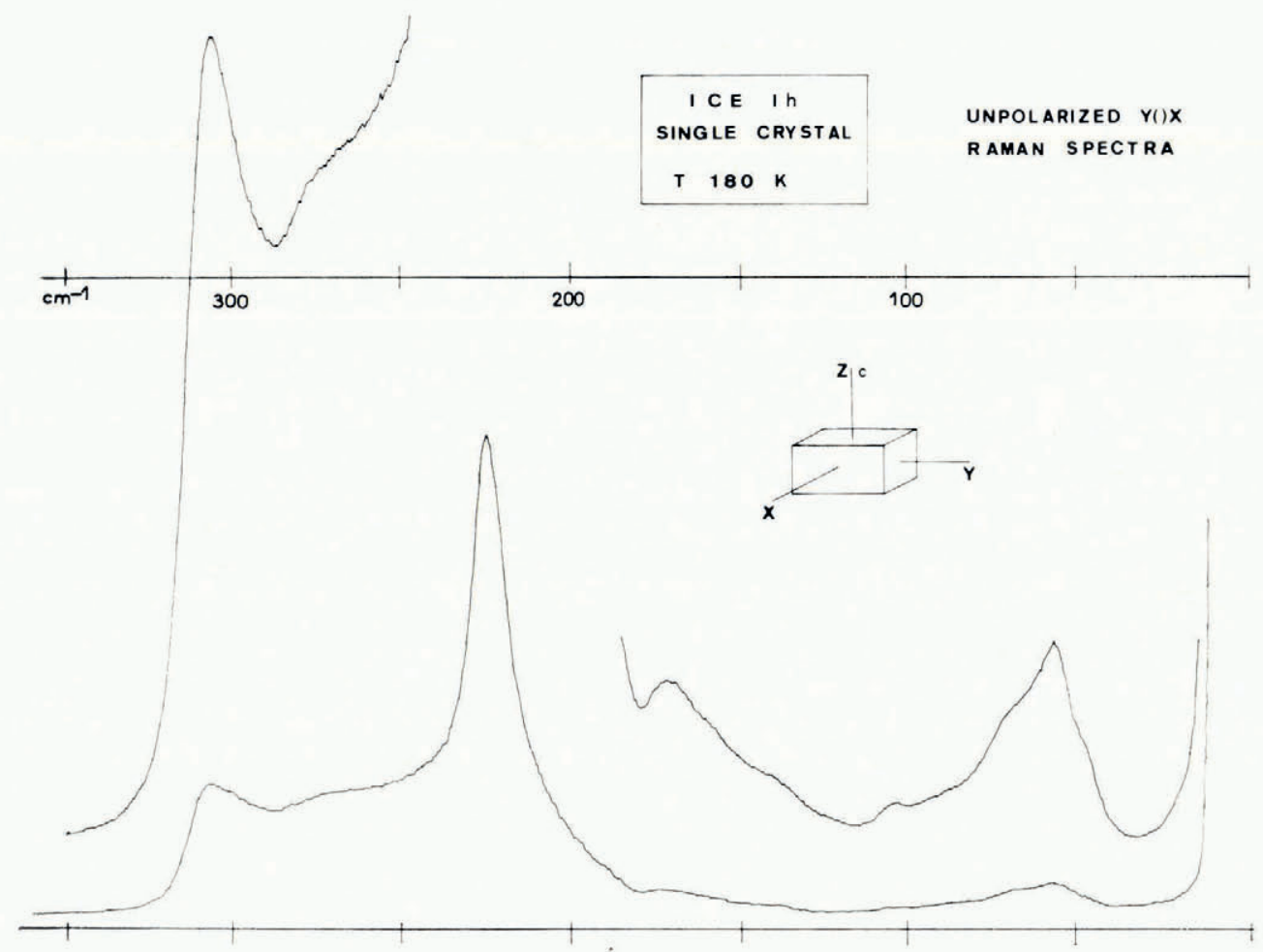

Fig. I. Unpolarized Raman spectra of single-crystal ice Ih at $180 \mathrm{~K}$.

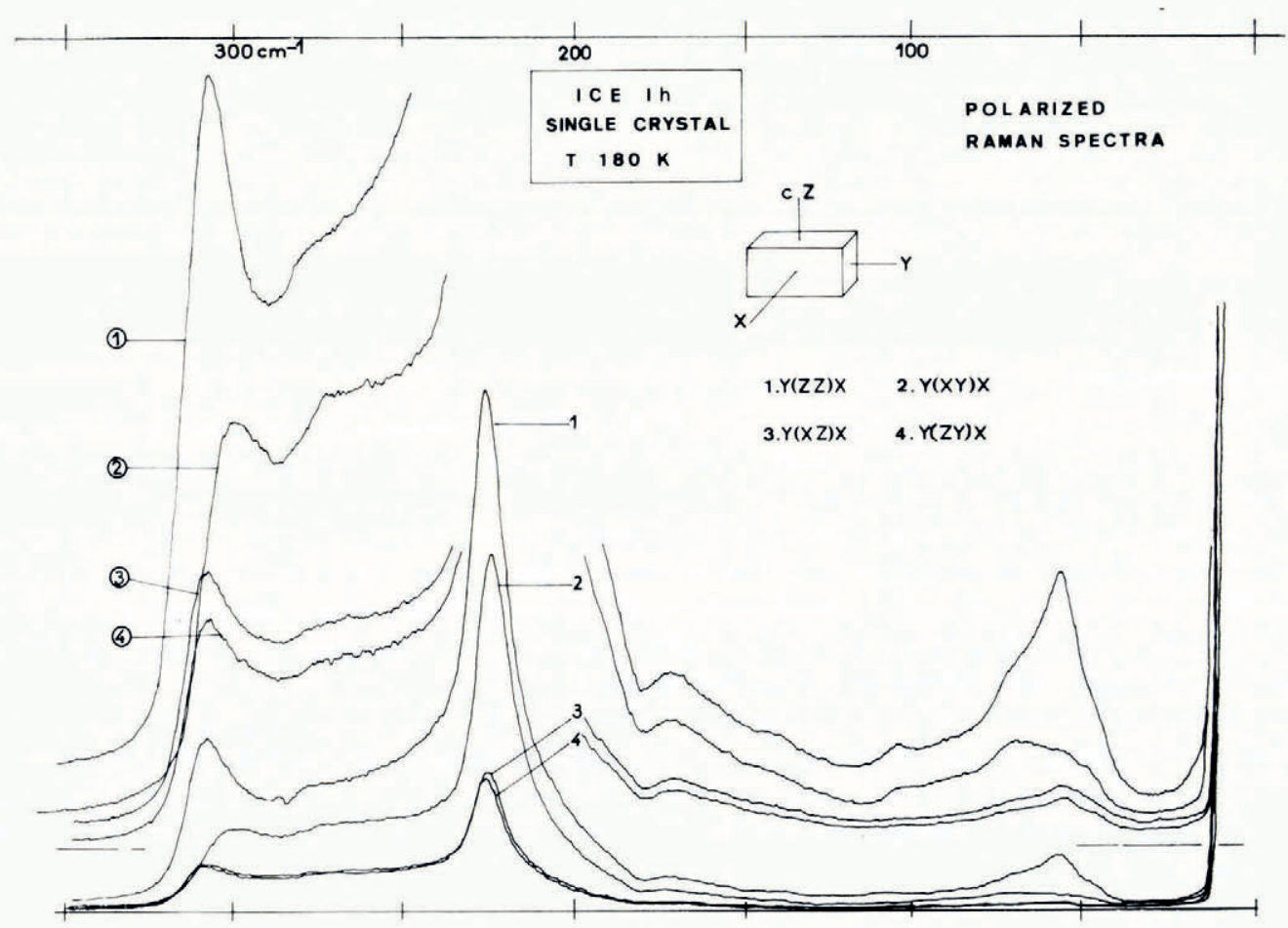

Fig. 2. Polarized Raman spectra of single-crystal ice Ih at $180 \mathrm{~K}$. 
In ice Ih the oxygen atoms are arranged in $D_{6} h^{4}$ symmetry, with four oxygen atoms in the unit cell. It is generally accepted that proton positions are governed only by the well-known Bernal-Fowler rules (1933) and that these proton positions are therefore disordered. The corresponding cubic form, ice Ic, is also generally considered to be disordered.

\section{Experimental methods AND SPEctra}

The Raman spectra were recorded in the range ${ }_{1} 5$ to $350 \mathrm{~cm}^{-1}$ with a $\mathrm{PH}_{\mathrm{I}}$ Coderg double monochromator and a Spectra-Physics 164 argon-ion laser (488o and 5 I $45 \AA$; typically I W) from pure transparent samples of $\mathrm{H}_{2} \mathrm{O}$ ice Ih single crystals, cut in the form of small parallelepipeds or cylinders according to the experiments planned. The recording temperatures were 77 and $180 \mathrm{~K}$, with polarized and unpolarized light, spectral slit widths used varied from 2 to $0.5 \mathrm{~cm}^{-1}$ and scanning speeds from 25 to $\mathrm{I} \mathrm{cm}-1 / \min$ (Figs $\mathrm{I}-3$ ). The spectra exhibit much fine structure but not as much as in Wong and others (1973) for polycrystalline samples. The reproducible features are listed in Table I together with the corresponding features from Wong and others (1973). The $r(Z Z) X$ polarization is very similar to the

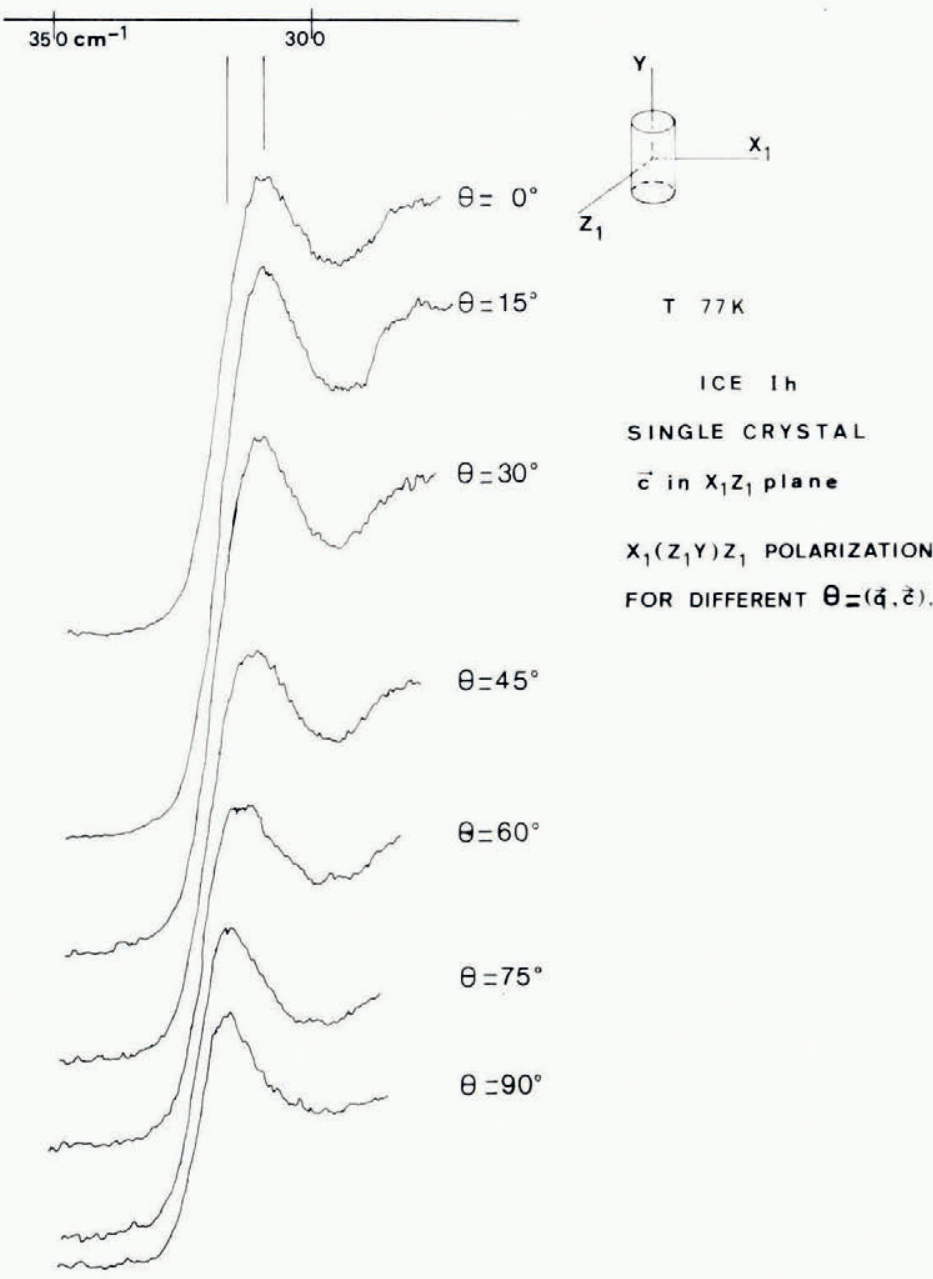

Fig. 3. $X_{1}\left(Z_{1} r\right) Z_{1}$ polarization for different $\theta=(\mathbf{q}, \mathbf{c})$ at $77 K$. 
spectrum with unpolarized light, and the differences between the four polarizations are not as great as is generally observed in ordered crystals. Nevertheless, depending on the polarization, one can notice, in addition to the different intensities, slight frequency shifts in the maxima near $225 \mathrm{~cm}^{-1}$, larger shifts $\left(c .8 \mathrm{~cm}^{-1}\right)$ in the maxima near $300 \mathrm{~cm}^{-1}$ (as previously observed by Faure and Chosson $\left.\left(\left[\mathrm{e}_{\mathrm{I}} 97 \mathrm{I}\right]\right)\right)$ and differing shapes for the maxima near $6 \mathrm{o} \mathrm{cm}^{-1}$ and for the shoulders near $270 \mathrm{~cm}^{-1}$ (Table I). These results show the interest of studying single crystals of ice Ih in polarized light, in spite of the proton disorder. In particular the observation of the two maxima near $300 \mathrm{~cm}^{-1}\left(307\right.$ and $298.8 \mathrm{~cm}^{-1}$ at $\left.180 \mathrm{~K}\right)$ is not possible in unpolarized light owing to the width of the peaks, and we believe the existence of these two maxima is important for the proposed interpretation of the spectrum.

TAble I. Frequencies in $\mathrm{cm}^{-1}$ of the features in the Raman SPECtrum of ice Ih $\left(\mathrm{H}_{2} \mathrm{O}\right)$

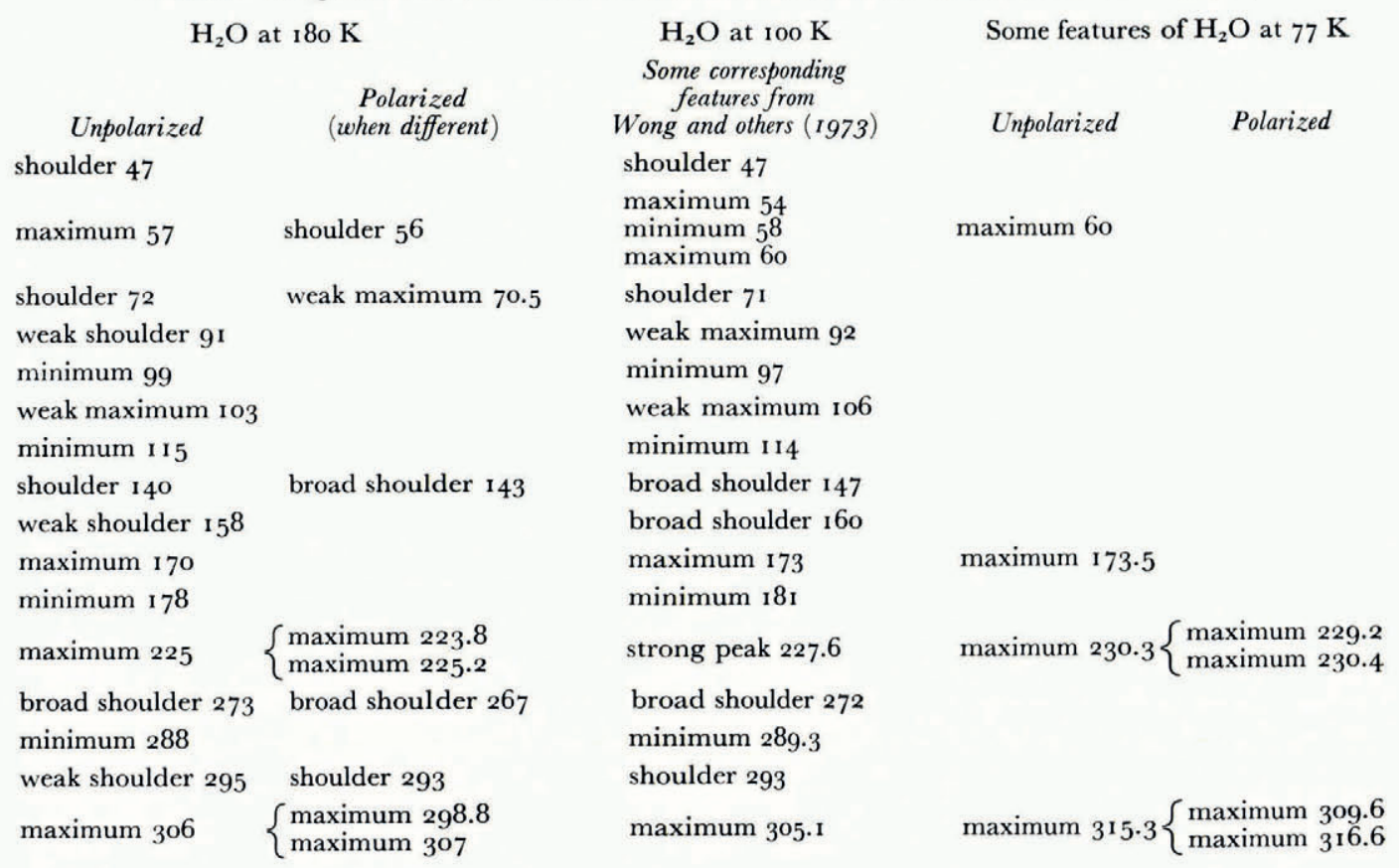

\section{Activity of ORDER-Allowed AND Disorder-Allowed MOdes}

The $D_{6 h}$ symmetry of the oxygen-atom lattice allows three modes $A_{1} g, E_{1} g$, and $E_{2}$ for first-order ordinary Raman scattering processes. Clearly however the spectra do not consist of three well-defined lines. The temperature dependence of intensity (Faure and Chosson, [ ${ }^{\mathrm{c}} \mathrm{r} 97 \mathrm{I} \mathrm{I}$ ) shows that the $c .300, c .225$, and $c .60 \mathrm{~cm}^{-1}$ maxima correspond to one-phonon processes. In fact the Raman spectrum is very similar to the frequency spectrum derived from slowneutron scattering experiments (Prask and others, 1968). Furthermore, first-order infrared processes are all forbidden in the $D_{6 h}$ symmetry of the oxygen atoms of ice Ih; however the translational infrared spectrum (Bertie and others, 1969 ) exists and is also very similar to this same derived frequency spectrum. The same vibrations seem to occur in both infrared and Raman spectra but with different relative intensities. (This simultaneous activity will direct us in the choice of the proposed interpretation.) Whalley and Bertie (1967) have given an explanation for these similarities. The disorder of the protons gives rise to what they call 
disorder-allowed modes in Raman and infrared first-order processes, not only for $\mathbf{q} \approx 0$ (q being the phonon wave vector) but also for $\mathbf{q}$ in the whole Brillouin Zone. The Raman spectrum is then due to these disorder-allowed modes together with the order-allowed $A_{1} g$, $E_{1} g$, and $E_{2}$ modes in the $D_{6} h$ symmetry.

A satisfactory description of the observed infrared and Raman intensities requires not only the knowledge of the frequencies at $\Gamma$ (centre of the Brillouin Zone) but also of the dispersion curves and the frequency spectrum.

The dynamical models already used (Kahane, unpublished; Faure, I969; Wong and others, 1973; Shawyer and Dean, 1972; Prask and others, 1972; Renker, 1973; Bosi and others, 1973) either are unable to account for the existence of translatory fundamentals up to $c .320$ $\mathrm{cm}^{-1}$, or use numerous force constants (ten for instance) and are therefore of doubtful physical significance. All these models use only short-range valence forces.

\section{TO-LO SPLITTINGS IN DISORDERED IGE-A SIMPLE DYNAMIGAL MODEL}

In ordered crystals, phonons active in first-order infrared absorption produce an electric dipole moment in the lattice, and the accompanying long-range electric fields lead to splittings between transverse optic and longitudinal optic modes (Poulet, unpublished; Loudon, r964; Poulet and Matthieu, [ $\left.{ }^{\mathrm{c}}{ }_{1970}\right]$ ). If these phonons are simultaneously active in the first-order Raman effect (a necessary condition being that the crystal lacks an inversion centre) the TO and LO modes can be observed by the Raman effect under appropriate experimental conditions (see for instance Arguello and others (1969)).

As we have seen in Section III, in ice Ih and Ic where the proton positions are nearly disordered, all the translational vibrations are simultaneously Raman and infrared active (at least weakly) and in particular those for $\mathbf{q} \approx 0$. If these vibrations are sufficiently delocalized, one can expect TO-LO splittings in the Raman spectrum. In particular the strong infrared absorption near $225 \mathrm{~cm}^{-1}$ will generate a TO-LO splitting and the Raman peaks near 225 and $300 \mathrm{~cm}^{-1}$ will be due to this splitting, since the Lyddane-Sachs-Teller relation $\omega_{\mathrm{LO}} / \omega_{\mathrm{TO}}=\left(\epsilon_{0} / \epsilon_{\infty}\right)^{\frac{1}{2}}$ applied to these maxima leads to a value of $c .1 .3$ for $\omega_{\mathrm{LO}} / \omega_{\mathrm{TO}}$ as against c. 1.23 for $\left(\epsilon_{0} / \epsilon_{\infty}\right)^{\frac{1}{2}}$.

We thus explain semi-quantitatively the existence of translational fundamentals beyond c. $250 \mathrm{~cm}^{-1}$ by TO-LO splittings. To be more quantitative one needs a dynamical model leading to TO-LO splittings. The simplest way of removing the inversion centre of the $D_{6} h$ symmetry and reaching the desired aim in dynamical calculations is to attribute to the oxygen atoms positive and negative effective charges, with opposite charges for two neighbouring oxygen atoms. The $D_{6} h$ symmetry lowers to $C_{6 v}$ and the different modes transform as indicated in Table II. $A_{\mathrm{I}}$ and $E_{\mathrm{I}}$ are "polar" modes. In the $(K, G, \rho)$ dynamical model we consider here, $K$ is the stretching constant for an $\mathrm{O}-\mathrm{O}$ bond, $G$ is the angle bending constant for an $\mathrm{O}-\mathrm{O}-\mathrm{O}$ angle and $\rho\left(\rho \equiv q^{2} / 4 \pi \epsilon_{0} a^{3}\right)$ accounts for the long-range interaction of the effective charges ( $q$ being the effective charge and $a$ the distance between two first-neighbour oxygen atoms). In this first step we have only three parameters.

Some indications concerning the calculation of the frequencies at the centre of the Brillouin Zone are given by Faure and Kahane ([ $\left.\left.{ }^{c_{I}}{ }_{97} I\right]\right)$. These frequencies expressed in $\kappa, G$, and $\rho$ are given in Table II for $\mathbf{q} \| \mathbf{c}$ and $\mathbf{q} \perp \mathbf{c}$.

The looseness of the selection and polarization rules on account of the proton disorder does not facilitate an unambiguous choice for the numerical values of $K, G$, and $\rho$. As our aim was to test the ability of this mixed Coulomb-valence-dynamical model to reproduce the high-frequency part of the translational spectrum, we chose the simple fit $A_{\mathrm{I}}(\mathrm{LO})=299 \mathrm{~cm}^{-1}$, $E_{1}(\mathrm{TO})=225 \mathrm{~cm}^{-1}$, and $B_{2}=\mathrm{I} 70 \mathrm{~cm}^{-1}$ (Table II). As well as accounting for the maxima near 300,225 , and $\mathrm{I} 70 \mathrm{~cm}^{-1}$, this model leads to a possible explanation for the frequency shifts already described as a function of polarization of the maxima near 300 and $225 \mathrm{~cm}^{-1}$ 
Table II. Calculated frequencies at $\Gamma$ with $(K, G, \rho)$ model for ice Ih

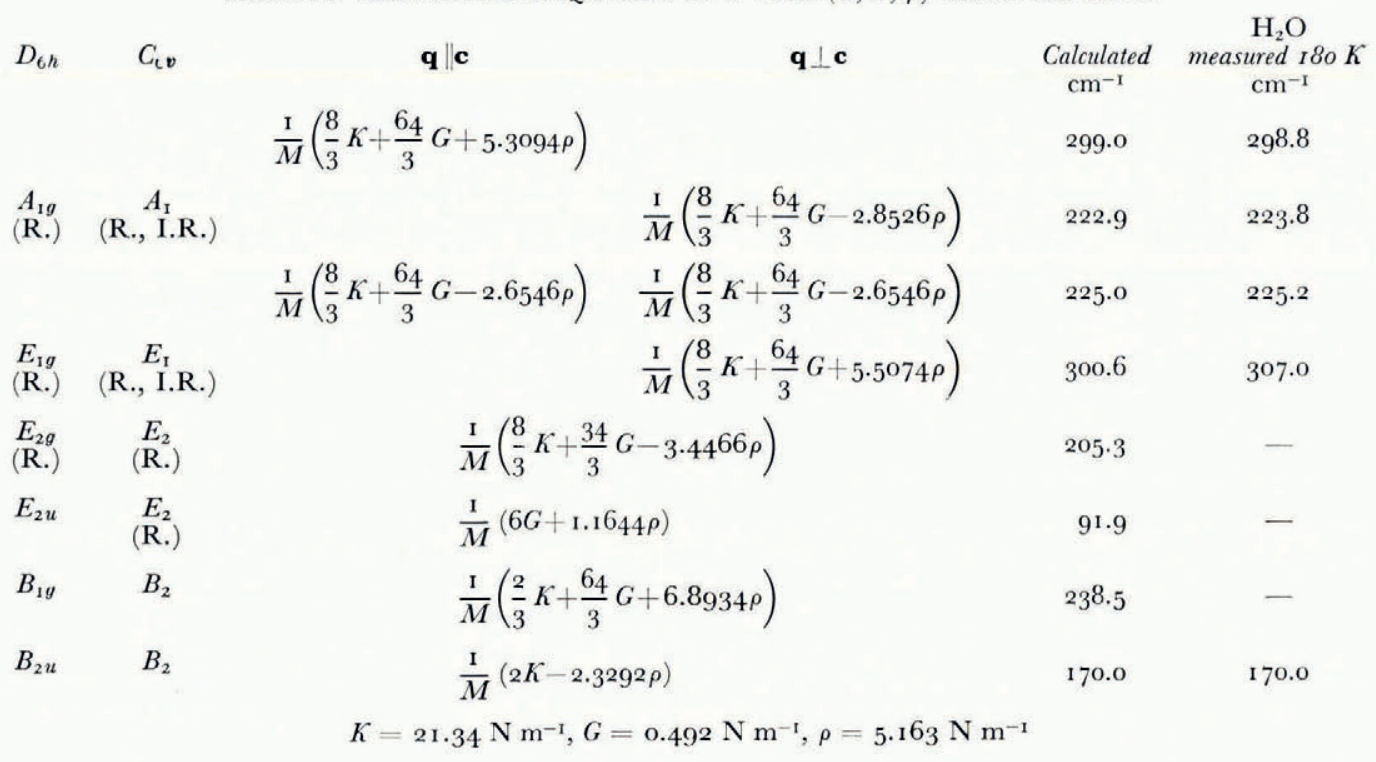

since the two calculated LO modes have slightly different frequencies, as have the two calculated TO modes. We do not find any frequency at $\Gamma$ near $60 \mathrm{~cm}^{-1}$, but for $E_{2}$ we find c. $92 \mathrm{~cm}^{-1}$. With only three parameters $K, G$, and $\rho$ it is not possible to lower this $E_{2}$ mode down to $c$. $60 \mathrm{~cm}^{-1}$ without destroying the good fit obtained for the $A_{\mathrm{I}}$ and $E_{\mathrm{I}}$ modes. On introducing two different angle bending constants $G$ and $G^{\prime}$ this becomes possible. With this $\left(\kappa, G, G^{\prime}, \rho\right)$ model we obtain the same numerical values as in Table II for $A_{1}(\mathrm{LO}), A_{\mathrm{I}}(\mathrm{TO})$, $E_{\mathrm{I}}(\mathrm{LO}), E_{\mathrm{I}}(\mathrm{TO})$ and the two $B_{2}$ modes, but $E_{2}=217.6 \mathrm{~cm}^{-1}$ and $E_{2}=57 \mathrm{~cm}^{-1}$ for $K=2 \mathrm{1} .34, G=8.034, G^{\prime}=-7.050$ and $\rho=5.163 \mathrm{~N} \mathrm{~m}^{-1}$ (details will be published later).

With the $(K, G, \rho)$ model, the dispersion curves and the frequency spectrum were calculated and compared with the corresponding measurements (Prask and others, I968; Renker, 1973; unpublished work by Renker and Parisot). They will be published elsewhere. The merely moderate agreement obtained for the very-low-frequency part of the translational spectrum (as expected, since $E_{2}$ is found at $c .9^{2} \mathrm{~cm}^{-1}$ and the calculated elastic constants are rather high) would be very likely to be improved by the use of the $\left(K, G, G^{\prime}, \rho\right)$ model.

\section{Diregtional effegts in ige}

The theory for polar modes in non-cubic crystals predicts the existence of "quasilongitudinal" and "quasi-transverse" modes, the frequencies of which vary with the angle $\theta$ between the phonon wave vector $\mathbf{q}$ and the optical $c$-axis. This was investigated in ice by rotating a single crystal in the form of a cylinder inside the low-temperature cell so as to obtain different values of $\theta$. In order to get maximum sensitivity, these polarized spectra were recorded in the $300 \mathrm{~cm}^{-1}$ region, since the observed frequency shifts near $300 \mathrm{~cm}^{-1}$ are greater than those near $225 \mathrm{~cm}^{-1}$. At $77 \mathrm{~K}$ the $X_{\mathrm{I}}\left(Z_{\mathrm{I}} Y\right) Z_{\mathrm{I}}$ polarization frequency varies from $309.5 \mathrm{~cm}^{-1}$ for $\theta \approx 0$ to $3 \mathrm{I} 7$ for $\theta \approx 90^{\circ}$ (Fig. 3). At the same temperature for another sample with the arrangement of Figure 2 the two different measured frequencies of the polarizations, which we ascribe to LO modes on the basis of the results of the $(K, G, \rho)$ model, are $309.6 \mathrm{~cm}^{-1}$ 
and $3^{16.6 \mathrm{~cm}^{-1}}$ (Table I). The important fact is that this $\theta$ dependence occurs (within the experimental error due to the width of the peaks) inside the interval between the two LO modes.

If this directional effect in ice Ih is indeed q-dependent (experiments are being undertaken to confirm this point), it would be an argument for the proposed explanation of the existence of translational frequencies up to $c .320 \mathrm{~cm}^{-1}$ in the Raman spectrum of Ice Ih, since qdependent directional effects are characteristic of uniaxial crystals possessing TO-LO splittings.

\section{Acknowledgements}

We are indebted to Dr J. Klinger for growing the single crystals and to Mr Merlin for the computer programming.

\section{REFERENCES}

Arguello, C. A., and others. I969. First-order Raman effect in wurtzite-type crystals, [by] C. A. Arguello, D. L. Rousseau and S. P. S. Porto. Physical Review, Second Ser., Vol. I8I, No. 3, p. 1351-63.

Bernal, J. D., and Fowler, R. H. 1933. A theory of water and ionic solution, with particular reference to hydrogen and hydroxyl ions. Journal of Chemical Physics, Vol. I, No. 8, p. 51 5 -48.

Bertie, J. E., and others. 1969. Absorptivity of ice I in the range $4000-30 \mathrm{~cm}^{-1}$, [by] J. E. Bertie, H. J. Labbé and E. Whalley. Journal of Chemical Physics, Vol. 50, No. 10, p. 4501-20.

Bosi, P., and others. 1973. On the problem of the vibrational spectrum and structure of ice Ih: lattice dynamical calculations, [by] P. Bosi, R. Tubino and G. Zerbi. Journal of Chemical Physics, Vol. 59, No. 9, p. $4578-86$.

Faure, P. 1969. Étude d'un modèle dynamique du réseau cristallin de la glace. Fournal de Physique, Tom. 30 , Nos. 2-3, p. $214-20$.

Faure, P. Unpublished. Étude théorique et expérimentale du spectre Raman basse fréquence de la glace. [Paper presented at the Xth European Congress on Molecular Spectroscopy, University of Liège, Belgium, 29 September-4 October i969.]

Faure, P., and Chosson, A. [ ${ }^{\mathrm{C}}$ I97 I.] Low frequency Raman spectrum of ice Ih. Tentative interpretation with a mixed Coulomb-valence dynamical model. (In Balkanski, M., ed. Proceedings of the second international conference on light scattering in solids (Paris, 7uly 19-23, 1971). Paris, Flammarion Sciences, p. 272-77.)

Faure, P., and Kahane, A. [ ${ }^{\mathrm{c}}$ 1971.] Modèle dynamique polaire de la glace Ih monocristalline. (In Nusimovici, M. A., ed. Phonons. Comptes rendus de la conférence internationale. Rennes, France, 197I. Paris, Flammarion Sciences, p. 243-47.)

Kahane, A. Unpublished. Recherches expérimentales et théoriques sur les propriétés optiques et la structure de la glace. [Dr. ès Sc. Phys. thesis, Université de Paris, 1962.]

Loudon, R. I964. The Raman effect in crystals. Advances in Physics, Vol. 13, No. 52, p. 423-82.

Poulet, H. Unpublished. Sur certaines anomalies de l'effet Raman dans les cristaux. [Dr. ès Sc. Phys. thesis, Université de Paris, 1955.]

Poulet, H., and Mathieu, J.-P. [ [ $\left.{ }^{\mathrm{c}} \mathrm{1} 970.\right]$ Spectres de vibration et symétrie des cristaux. Paris, etc., Gordon et Breach.

Prask, H. J., and others. 1968. Frequency spectrum of hydrogenous molecular solids by inelastic neutron scattering: hexagonal $\mathrm{H}_{2} \mathrm{O}$ ice, [by] H. J. Prask and H. Boutin, and S. Yip. Journal of Chemical Physics, Vol. 48, No. 8, p. $3367-76$.

Prask, H. J., and others. 1972. Ice I-lattice dynamics and incoherent neutron scattering, [by] H. J. Prask, S. F. Trevino, J. D. Gault and K. W. Logan. Fournal of Chemical Physics, Vol. 56, No. 7, p. 32 I 7-25.

Renker, B. 1973. Lattice dynamics of hexagonal ice. (In Whalley, E., and others, ed. Physics and chemistry of ice: papers presented at the Symposium on the Physics and Chemistry of Ice, held in Ottawa, Canada, I4-18 August 1972. Edited by E. Whalley, S. F. Fones, L. W. Gold. Ottawa, Royal Society of Canada, p. 82-86.)

Renker, B., and Parisot, G. 1976. Lattice dynamics of hexagonal ice. Rapport Anmuel de l'Institut Laue-Langevin, Grenoble, Annexe, p. 69-70.

Shawyer, R. E., and Dean, P. 1972. Atomic vibrations in orientationally disordered systems: II. Hexagonal ice. Fournal of Physics, $C$, Vol. 5, No. 10, p. 1028-37.

Whalley, E., and Bertie, J. E. 1967 . Optical spectra of orientationally disordered crystals. I. Theory for translational lattice vibrations. Fournal of Chemical Physics, Vol. 46, No. 4, p. 1264-70.

Wong, P. T. T., and Whalley, E. 1976. Optical spectra of orientationally disordered crystals. VI. The Raman spectrum of the translational lattice vibrations of ice Ih. Journal of Chemical Physics, Vol. 65, No. 2, p. 829-36.

Wong, P. T. T., and others. 1973. The Raman spectrum of the translational lattice vibrations of ice Ih, [by] P. T. T. Wong, D. D. Klug and E. Whalley. (In Whalley, E., and others, ed. Physics and chemistry of ice: papers presented at the Symposium on the Physics and Chemistry of Ice, held in Ottawa, Canada, 14-18 August 1972. Edited by E. Whalley, S. J. Jones, L. W. Gold. Ottawa, Royal Society of Canada, p. 87-92.) 


\section{DISGUSSION}

W. B. Камв: To what extent is the explanation of TO-LO splitting given by your effectivecharge model basically the same as, or different from, the explanation given by Klug and Whalley in the previous paper?

P. FAure: We propose to explain the existence of translational frequencies up to about 320 $\mathrm{cm}^{-1}$ in the Raman spectra of ice Ih and Ic by the TO-LO splittings necessary from the observed infrared absorption. We believe that this explanation is basically the same as the one given by Klug and Whalley. In order to generate TO-LO splittings in the dynamical calculation in a simple manner, we use positive and negative permanent charges and this is the difference with Klug and Whalley's more elaborate model.

We had already used this explanation involving TO-LO splittings for ice in a previous paper but expressed in a different way.

E. Whalley: The relation between the models of Faure and Chosson and of Klug and Whalley can be summarized as follows. Both attribute the scattering and absorption at c. $300 \mathrm{~cm}^{-1}$ to LO modes. Faure and Chosson interpret this in molecular terms by assuming that alternate water molecules carry a positive and negative charge, whereas Klug and Whalley assume that the molecules are uncharged but each has an effective charge tensor which describes the dipole moments induced by translations. In ordered cubic ice the charge tensors of nearest-neighbour molecules have the same magnitude but opposite sign. In disordered ice, the charge tensors presumably vary from molecule to molecule in an irregular manner depending on the orientation of the molecule and its neighbours. 